\title{
Examining constipation assessment and management of patients with advanced cancer receiving specialist palliative care: a multi-site retrospective case note review of clinical practice
}

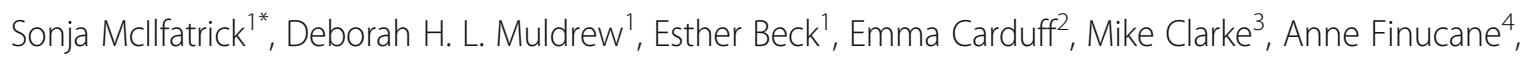
Lisa Graham-Wisener ${ }^{3}$, Phil Larkin ${ }^{5}$, Noleen K. McCorry ${ }^{3}$, Paul Slater ${ }^{1}$ and Felicity Hasson ${ }^{1}$

\begin{abstract}
Background: Constipation is a common symptom for patients receiving palliative care. Whilst international clinical guidelines are available on the clinical management of constipation for people with advanced cancer receiving specialist palliative care (SPC), the extent to which the guidelines are implemented in practice is unclear. This study aimed to examine clinical practices for the assessment and management of constipation for patients with advanced cancer within inpatient SPC settings.
\end{abstract}

Methods: A multi-site retrospective case-note review was conducted, consisting of 150 patient case-notes from three inpatient SPC units across the United Kingdom between August 2016 and May 2017. The variables selected for review were determined by the recommendations within the clinical guidelines. Descriptive statistics, cross tabulation, chi square, and bivariate correlations were used to examine clinical practices compared to policy guidelines for the assessment and management of constipation. Reporting was structured by the STROBE checklist for observational research (Additional File 2).

Results: A comprehensive assessment, including a full history and performing a physical exam, was recorded for 109 patients (73\%), however, no standardised documentation was utilised. Assessment was nurse led, with variable involvement across sites of other members of the multidisciplinary team (MDT). Education on prevention was documented in 30 (20\%) case-notes, and 53\% recorded evidence of non-pharmacological intervention. Age, gender, and reason for admission did not impact on the likelihood of receiving a comprehensive assessment, education, or non-pharmacological intervention, however, significant differences were evident between sites. Pharmacological management was well developed and aligned to the guidelines however, 33\% of patient case-notes recorded no information on the titration of laxatives. Twelve percent of patients experienced partial or complete bowel obstruction, and management strategies were variable.

(Continued on next page)

\footnotetext{
*Correspondence: sj.mcilfatrick@ulster.ac.uk

${ }^{1}$ Institute of Nursing and Health Research, Ulster University, Shore Road,

Newtownabbey, Co Antrim BT37 0QB, UK

Full list of author information is available at the end of the article
}

(c) The Author(s). 2019 Open Access This article is distributed under the terms of the Creative Commons Attribution 4.0 International License (http://creativecommons.org/licenses/by/4.0/), which permits unrestricted use, distribution, and reproduction in any medium, provided you give appropriate credit to the original author(s) and the source, provide a link to the Creative Commons license, and indicate if changes were made. The Creative Commons Public Domain Dedication waiver (http://creativecommons.org/publicdomain/zero/1.0/) applies to the data made available in this article, unless otherwise stated. 


\begin{abstract}
(Continued from previous page)
Conclusions: Constipation management is driven by a pharmacological approach, with little evidence of the implementation of preventative and non-pharmacological strategies. The nurse plays a key coordinating role in assessment; however, involvement and roles of the wider MDT varies. Accurate recording of care is essential when examining clinical practice and identifying areas for improvement. Further education is needed to equip HCPs with the knowledge and skills to ensure consistency in assessment and implementation of appropriate non-pharmacological/ preventative strategies.
\end{abstract}

Keywords: Constipation, Symptom management, Palliative care, Hospice: specialist palliative care, Chart review

\section{Background}

Constipation is identified by unsatisfactory defecation due to infrequent stools, difficulty passing stools, or the sensation of incomplete emptying [1]. This contributes to considerable physical and psychological suffering for patients and their families [2]. It is one of the most frequent gastrointestinal complications encountered in clinical practice in Western societies [3], with prevalence rates increasing in older adults across community [4] nursing homes [5], and specialist palliative care [6] settings. Whilst constipation affects approximately $40 \%$ of patients receiving palliative care [7], this figure increases in specialist palliative care (SPC) to greater than 66\% [6]. Mercadante [6] assessed the change in prevalence of constipation in patients with advanced cancer after one week of receiving support from SPC. Patients with low bowel function (bowel function index $\leq 28$ ) experienced worsening of their symptoms, and patients with normal bowel function at initial assessment saw a worsening in their condition due to lack of prevention or subsequent under-treatment. A systematic review of constipation in SPC settings identified challenges for the assessment and management of this symptom, including a lack of standardised assessment, an overemphasis on pharmacological intervention, and lack of preventative and non-pharmacological intervention [8]. Fragmented approaches to constipation management were highlighted in a European Report on the burden of constipation in an ageing population [9], and similar challenges have been identified in previous hospice-based studies, identifying a need to improve the overall clinical practices of assessment and management of this symptom [10].

To guide clinical practice, a review of guidelines identified twenty-two generic clinical guidelines for constipation across North America, Europe, and Asia [11]. It was found, however, there was only one guideline developed specifically for palliative care, developed according to the principles of the ADAPTE $^{1}$ process [12] (Additional file 1). These guidelines provide a useful starting point for evidencebased practice as their recommendations are well supported by the research literature. Such recommendations include: the need for a comprehensive assessment using the Rome III criteria [13]; a complete documentation of medical history; and the use of physical examination as part of the comprehensive assessment process [14-17]. In order to ensure effective management of constipation, it is recommended that equal attention is paid to optimised toileting, lifestyle modifications, and adjustment of activity levels, alongside pharmacological management [18]. Very recent clinical guidelines have been developed by the European Society for Medical Oncology for the diagnosis, assessment, and management of constipation [19], and similar key recommendations are made compared to the previous guidelines. This includes the need for a comprehensive assessment, and a balance of strategies for prevention and self-care and prescribed laxative therapy. It is noteworthy that despite a systematic review of clinical trials highlighting no evidence to support the use of one laxative over another [20], previous research in both the UK and USA identified preferences for specific laxatives, such as Senna and Sodium Docusate $[10,21]$. It is also noted that clinical record keeping is an integral component in the delivery of quality healthcare $[22,23]$, and essential to ensure high quality care. Whilst key areas have been identified by the guidelines and supported by the literature, questions exist for these specific guidelines but also more generally across oncology guideline implementation around the extent of their implementation, HCP compliance to the guidelines across patients, and impact in clinical practice [24]. There is a dearth of real-world, patient-level, clinical evidence regarding the management of constipation for people with advanced cancer in SPC settings.

\section{Methods}

Aim

To examine the clinical practice for the assessment and management of constipation for patients with advanced cancer within SPC settings.

\section{Design}

A descriptive, retrospective, observational study was conducted. Multidisciplinary case-notes of patients $(n=150)$ were reviewed in three SPC inpatient units. These notes were reviewed using a process guided by Gilbert's [25] eight criteria, which includes abstractor training, explicit case selection, clear definition of variables, standardised abstraction forms, meetings with abstractors to resolve disputes, 
monitoring performance of abstractors, blinding of abstractors, and testing for inter-rater agreement. These criteria have been previously applied within palliative care research focusing on end of life care provision, medication use, and hospitalization [26] and were therefore deemed appropriate for use in the current study. Reporting was structured by the STROBE checklist for observational research to provide a rigorous structure for reporting and to ensure sufficient information is presented to allow for replication [27] (Additional file 2).

\section{Setting}

In the United Kingdom (UK) in 2014/2015, at least 36, 000 people used SPC inpatient services; $80 \%$ of these patients had a diagnosis of cancer, and typically were admitted as part of a planned series of short stays between one and four days [28]. Data were collected from a convenience sample of three SPC inpatient units associated with one hospice organisation. The sites included represented three distinct regions of the UK, had previously established collaborative links through involvement in other research projects, and had expressed an interest in this particular topic. The units comprised on average 22 beds, and admitted on average 329 patients each year. Patients admitted from August 2016 to May 2017 were included in the review.

\section{Participants}

On average, 987 patients are admitted to the three hospices annually, of which approximately two thirds may experience constipation. In conjunction with the research leads at each clinical site, 150 patient case notes were identified as an appropriate sample (50 per clinical site) within a ten-month period to enable a suitable comprehensive picture within the timeframe and available resources. Case-notes were reviewed chronologically from the beginning of the selected time-period until 150 had been identified which met the criteria:

- Adult patients with advanced cancer;

- Aged over 18 years;

- Admitted to the hospice in a specified period (if a patient was readmitted, data were only extracted for their first admission in this time period); and

- Constipation was noted as a problem in their multidisciplinary records as per the Rome III criteria.

Patient records were reviewed and data extracted using a standardised data extraction form, adapted from clinical guidelines for the management of constipation [18], and in consultation with experts from the clinical sites (See Additional file 1).

\section{Data collection}

Six health care professionals (HCPs) (five nurses and one physiotherapist) with an interest in this clinical area and working in the hospice volunteered as data abstractors. A training session was held prior to data abstraction to clarify inclusion criteria and practical considerations when undertaking the review. Data abstractors accessed the patient's clinical notes, either through an online system or paper records, depending on accessibility at the site. After data abstraction from five patient case-notes per site, a follow up meeting was held to discuss any problems and ensure consistency in data recording.

\section{Variables}

Key variables for the review included assessment, prevention, pharmacological and non-pharmacological management strategies, opioid induced constipation (OIC), and intestinal obstruction. Additional data included patient demographics, medical history, and reason for referral. The variables selected for review were determined by the recommendations within the clinical guidelines [18]. The use of a standardised form, multiple training sessions, and ongoing discussions between the research team and data abstractors increased confidence in the standardised completion of the forms.

\section{Bias}

To minimise the risk of selection bias, consecutive, chronological cases were selected to prevent data abstractors picking cases reflective of better practice. Measurement bias was managed by selecting data abstractors who were separate to the research team and had no prior investment in the project. To prevent the risk of publication bias, all findings from the review are presented, including ones which may demonstrate poor documentation or poor clinical practice.

\section{Data analysis}

Data were entered into IBM SPSS Statistics v23 and descriptive analysis undertaken. Variables were compared across sites for similarities and differences. Cross tabulation and chi squared tests were used to examine differences across variables. Bivariate correlation examined relationships between continuous variables. If "not recorded" was noted for a question in more than $15 \%$ of clinical case-notes, it has been discussed in the results as this is a commonly cited maximum for acceptable missing data $[29,30]$.

\section{Ethics}

The study protocol, including case note review, was approved by the Office for Research Ethics Committees Northern Ireland (ORECNI) (REC Reference 16/WM/ 0352). To access case notes, each hospice site's governance committee granted approval. Patient data were anonymised 
before being transferred to the research team, ensuring no patient could be identified within the data.

\section{Results}

\section{Demographic profile}

One hundred and fifty case-notes were reviewed (see Table 1). The mean age of patients was 69 years $(\mathrm{SD}=$ 12.09). Over half of patients were female $(n=85 ; 56.7 \%)$, and the main reason for admission was noted as symptom control $(n=71 ; 47.3 \%)$. A third of patients were recorded as living independently prior to admission $(n=$ $50 ; 33.3 \%)$ with family support $(n=132 ; 88.0 \%)$. The most frequent primary cancer sites were upper gastrointestinal ( $n=35 ; 23.4 \%)$, lung ( $n=29 ; 19.3 \%)$, and urological $(n=20 ; 13.3 \%)$. The mean length of stay in the SPC inpatient unit was 18.83 days. Patients were prescribed on average 1.25 laxatives $(\mathrm{SD}=1.10)$ and 1.45 opioids $(\mathrm{SD}=1.03)$. Medicines which acted on the gastrointestinal system were prescribed most frequently (mean $=2.31 ; \mathrm{SD}=1.40)$, followed by central nervous system drugs $($ mean $=2.26 ; \mathrm{SD}=1.91)$ and drugs specifically for pain $($ mean $=2.16 ; \mathrm{SD}=1.52)$.

\section{Main findings}

The results from the case note review are noted and summarised against the key areas as outlined within the clinical guideline recommendations (see Table 2). The results from each of these respective areas are then outlined.

\section{Constipation assessment}

A comprehensive assessment, including taking a full history and performing a physical exam, was recorded for 109 patients $(73 \%)$. On average $2.29(\mathrm{SD}=2.00)$ physical symptoms were recorded, the most frequent including infrequent bowel movements $(n=68 ; 45.3 \%)$, nausea $(n=$ 57; 38.0\%), abdominal pain ( $n=5033.3 \%)$, vomiting ( $n=$ $43 ; 28.7 \%)$, and poor appetite $(n=34 ; 22.7 \%)$. At one site patients were statistically more likely to receive a comprehensive assessment than the other two sites $\left(\mathrm{X}^{2}(2, N=\right.$ $145)=6.048, p=.049)$. Age $(p=.51)$, gender $(p=.31)$, level of independence $(p=.53)$, and reason for admission (end of life care compared to physical or psychological support) $(p=.18)$ did not significantly impact on the likelihood of receiving a comprehensive assessment.

A lack of standardised documentation for assessment was evident. Data abstractors noted the use of both online and paper notes to document bowel assessment, making it more challenging to access all the relevant information. The Bristol Stool Chart (BSC) [31] was recorded for 144 (96\%) patients within $24 \mathrm{~h}$ of admission, however, it was unclear if the BSC was used to reassess constipation during their time at the hospice. Two sites reported a "top to toe" assessment for 20 patients (13.3\%), suggesting a full physical exam took place during the assessment.
The nurse was involved in 127 (84.7\%) of initial assessments across the three sites, however, variability was evident in the involvement of other members of the MDT. At one site, assessments were conducted solely by the nurse $(n=28 ; 56 \%)$, doctor $(n=7 ; 14 \%)$, or HCA $(n=2$; $4 \%)$, and $10 \%(n=5)$ were conducted by both a doctor and nurse. The second site had $100 \%(n=50)$ patients assessed by the doctor, nurse, and HCA. The third site had 39 patients (78\%) assessed by both the doctor and nurse, eight patients (16\%) assessed solely by the nurse, and two patients (4\%) assessed solely by the doctor.

A quarter of case-notes had no recorded information on the relevance or use of digital rectal examination (DRE). Twenty-five case-notes (17\%) recorded that a DRE had been performed after three or more days without a bowel movement. Only two case notes (1\%) reported completion of a DRE when the patient complained of incomplete evacuation. The use of a DRE was not applicable to $50 \%$ of case-notes reviewed $(n=75)$.

\section{Constipation management}

These findings will be focused on the key areas of prevention, non-pharmacological management, and pharmacological management.

\section{Prevention}

Education on preventative and non-drug measures was documented in $30(20 \%)$ reviewed case-notes, with the majority provided at one site. Participants at one site were significantly more likely to receive education compared to the other two sites $\left(\mathrm{X}^{2}(2, N=145)=69.076\right.$, $p<.001)$. One site did not provide any documentation in relation to the provision of education on preventative measures. Age $(p=.70)$, gender $(p=.19)$, and reason for admission (end of life care compared to physical or psychological support) $(p=.36)$ did not significantly impact on the likelihood of receiving education. However, patients who did not require assistance with mobility were more likely to receive education on preventative and non-drug measures $\left[\mathrm{X}^{2}(3, N=142)=12.56, p=.006\right]$ than those requiring assistance or who were bed-bound.

\section{Non-Pharmacological management}

Non-pharmacological strategies were recorded in 79 patient case-notes $(53 \%)$. Such strategies included considerations of diet and fluids $(n=55 ; 37 \%)$, ensuring privacy $(n=52 ; 35 \%)$, mobility $(n=46 ; 31 \%)$, and optimised toileting $(n=28 ; 19 \%)$. Evidence of non-pharmacological strategies were not explicitly recorded on 41 case-notes (27\%), and the remaining $20 \%$ of case-notes identified nonpharmacological strategies as not discussed or not applicable. Age $(p=.55)$, gender $(p=.86)$, level of independence $(p=.43)$, and reason for admission (end of life care compared to physical or psychological support) $(p=.46) \mathrm{did}$ 
Table 1 Demographic profile of patients

\begin{tabular}{|c|c|c|}
\hline \multicolumn{2}{|l|}{ Characteristics } & \multirow{2}{*}{$\frac{N(\%)}{50(33.3)}$} \\
\hline Location & Northern Ireland (Belfast) & \\
\hline & Scotland (Edinburgh) & $50(33.3)$ \\
\hline & England (West Midlands) & $50(33.3)$ \\
\hline \multirow[t]{2}{*}{ Gender } & Male & $65(43.3)$ \\
\hline & Female & $85(56.7)$ \\
\hline \multirow[t]{4}{*}{ Reason Admitted } & $\begin{array}{l}\text { Symptom Control (Physical } \\
\text { or Psychological) }\end{array}$ & $82(54.7)$ \\
\hline & End of Life Care & $65(43.3)$ \\
\hline & Other & $1(.7)$ \\
\hline & Missing & $2(1.3)$ \\
\hline \multirow[t]{5}{*}{ Referral Source } & Specialist Palliative Care Team & $65(43.3)$ \\
\hline & Hospital (including outpatients) & $50(33.3)$ \\
\hline & $\begin{array}{l}\text { Community Referral (including General } \\
\text { Practitioner and Nursing home) }\end{array}$ & $29(19.3)$ \\
\hline & Not Recorded & $2(1.3)$ \\
\hline & Missing & $4(2.7)$ \\
\hline \multirow[t]{12}{*}{ Primary Cancer Site } & Upper Gl & $35(23.4)$ \\
\hline & Lung & $29(19.3)$ \\
\hline & Urological & $20(13.3)$ \\
\hline & Breast & $11(7.3)$ \\
\hline & Colorectal & $11(7.3)$ \\
\hline & Gynaecological & $11(7.3)$ \\
\hline & Haematological & $9(6.0)$ \\
\hline & CNS & $8(5.3)$ \\
\hline & Head and Neck & $7(4.7)$ \\
\hline & Skin & $3(2.0)$ \\
\hline & Bone & $2(1.4)$ \\
\hline & Other & $4(2.7)$ \\
\hline \multirow[t]{5}{*}{ Mobility } & Independent & $50(33.3)$ \\
\hline & Assistance of One & $34(22.7)$ \\
\hline & Assistance of Two & $31(20.7)$ \\
\hline & Bed Bound & $32(21.3)$ \\
\hline & Missing & $3(2.0)$ \\
\hline \multirow[t]{3}{*}{ Family Support } & Yes & $132(88.0)$ \\
\hline & No & $11(7.3)$ \\
\hline & Missing & $7(4.7)$ \\
\hline
\end{tabular}

not significantly impact on the likelihood of receiving non-pharmacological intervention. However, there were statistically significant differences between sites (X2 (2, $N=142)=11.962, p=.003)$.

\section{Pharmacological management}

Laxatives were recorded for 144 (96\%) patients. The most frequently administered laxative was Sodium Docusate, a softening laxative, with approximately a quarter of patients
$26 \%(n=39)$ patients receiving this as their primary laxative and $19 \%(n=28)$ receiving it as a secondary laxative. This was followed by Senna, a stimulant, with $18 \%$ of patients $(n=27)$ receiving it as a primary laxative and a further $11 \%$ $(n=17)$ receiving it as a secondary laxative. Of the patients who required multiple laxatives $(n=115)$, a combination of a softener and a stimulant were used in 59\% of cases $(n=$ 68 ). As would be expected, suppositories were more commonly used as a third line of pharmacological management, 
Table 2 Case note comparison to guidelines

Case-note review question

All sites $n(\%)$ yes

Clinical Guideline: Assessment

1.1 A thorough history and physical examination are recommended as essential components of the assessment process.

Constipation assessment scales are not recommended for routine use.

1.3 A digital rectal examination (DRE) is required to exclude faecal impaction if it has been more than 3 days since the last bowel movement or if the patient complains of incomplete evacuation

1.5 A plain film of the abdomen (PFA) is not recommended for routine evaluation but may be useful in combination with history

Clinical Guideline: Education

2.1 Education on the importance of non-drug measures is essential to enable patients and caregivers to take an active role in constipation prevention.

Clinical guidelines: Management

3.1 Attention should be paid to the provision of optimised toileting while ensuring adequate privacy and dignity.

3.2 Consideration should be given to lifestyle modification (adjustment of diet and activity levels within a patient's limitations)

Where there is no evidence to differentiate between medications in terms of efficacy, tolerability and side effect profile, and where clinical expertise allows, the medication with lowest cost base should be used.

Was a comprehensive assessment carried out?

Was an assessment tool used?

aDRE performed when it's been

3 or more days since last evacuation

complains of incomplete evacuation

Was a PFA performed?

Was education on non-drug measures recorded?

a'Was there evidence of consideration of optimised toileting?

$28(19)$

a'Was there evidence of consideration of privacy?

aWas there evidence of consideration of diet and fluids?

aWas there evidence of consideration of mobility?

$46(31)$

Primary Laxative (PL): Bisacodyl

5 (3)

PL: Senna

PL: Lactulose and examination in certain patients

PL: Glycerol

PL: Docusate

PL: Sodium Picosulphate

PL: Macrogols

PL: Other

PL: None administered

4.3 The combination of a softening \& stimulating laxative is often required. Optimisation of a single laxative is recommended prior to the addition of a second agent.

Was a combination of a softening and a

Was optimisation of a single laxative achieved prior to the addition of a second agent?

4.4 The laxative dose should be titrated daily or alternate days according to response.

awas the laxative dose titrated: Daily

Clinical guidelines: Opioid induced constipation

5.1 The development of OIC should be anticipated. A bowel regimen should be initiated at the commencement of opioid therapy

5.2 In the management of $\mathrm{OIC}$ optimised monotherapy with a stimulant laxative is essential followed by the addition of a softener if required.

ans the laxative dose titrated: On alternate days

Was a bowel regimen initiated at the commencement of opioid therapy?

Was optimisation of a stimulant laxative achieved prior to the addition

of a softening laxative?

In patients with partial IO: was the use of a

6.1 A stool softener should be considered in partial intestinal obstruction (IO).

Stimulant laxatives should be avoided.

6.2 In complete 1O, the use of all laxatives should be avoided as even softening laxatives have some peristaltic action. stool softener considered?

In patients with partial IO: were stimulant laxatives avoided? 1 (8)

In patients with complete IO: were all laxatives avoided? 
with Bisacodyl suppositories ( $\mathrm{n}=17 ; 11 \%)$ and Glycerin suppositories $(n=13 ; 9 \%)$ ranking as the top two third level treatments. In a third of patient case-notes $(n=49 ; 33 \%)$, no information was recorded regarding the titration of laxatives. Titration of laxatives daily or on alternate days were recorded for 13\% $(n=20)$ and $7 \%(n=11)$ of patients respectively. Daily titration varied from 0 to $30 \%$ across sites.

\section{Opioid induced constipation (OIC)}

Eighty percent $(n=120)$ of patient notes evidenced receipt of opioids; 17 of whom were on more than three opioids. Patients who were prescribed a higher number of opioids were also prescribed a higher number of laxatives $(p=.036)$. Out of the 120 patients receiving opioids, $17(14.2 \%)$ achieved optimisation of a stimulant prior to the addition of a softening laxative. Details on optimisation of a stimulant prior to the addition of a softening laxative was not recorded for $18.3 \%$ of patients $(n=22)$.

\section{Intestinal obstruction}

Partial or complete bowel obstruction was not applicable to the majority of patients $(n=132)$. In the 16 patients who had data recorded regarding the use of a stool softener for partial intestinal obstruction, $50 \%$ had received a softener $(n=8)$ and $50 \%$ had not $(n=8)$. Stimulants were only avoided in one patient with partial obstruction. Seven case-notes recorded complete intestinal obstruction, only one of which showed the avoidance of all laxatives.

\section{Discussion}

This study examined the recorded clinical practices of the assessment and management of constipation for patients with advanced cancer in three SPC inpatient units, and identified variations within and across sites in one organisation in both assessment and management practices from clinical guidelines recommendations.

Approximately three quarters of patients in this study received a comprehensive assessment, and other related symptoms such as nausea and vomiting were also recorded, demonstrating good clinical practice and a holistic approach to assessment. Globally it is advocated in both clinical guidelines and research that the assessment of constipation should combine the following elements: use of the Rome III criteria [13]; a medical history; and a physical exam [14-18]. In the hospice population, great diversity in the physical capacity of individuals (33.3\% independent and $21.3 \%$ bedbound), calls for assessment to consider not just the patient's bowel movements, but also a full history of their general health, needs, and circumstances as part of person-centred, holistic palliative care [32]. However, the findings showed no evidence of the use of standardised documentation for assessment or any further follow up, therefore, this may contribute to subjectivity in the assessment process and potentially overlooking patients who are constipated but their symptoms not appropriately documented to help reach a diagnosis.

The guidelines identify best practice as both constipation assessment and management delivered within a MDT with a clearly identified clinical lead and active communication between all team members [18]. Furthermore, a recent meta-synthesis of qualitative evidence identified the key coordinating role of the nurse in palliative care between the patient, family, and other HCPs as a fundamental aspect of their overall role [33]. In line with the guidelines and this meta-synthesis, the nurse had a leading role in the assessment and management of constipation, with variable involvement from other members of the MDT as appropriate and when required. Possible reasons for variability may be attributable to limits in guideline diffusion within the SPC unit, or to perceived role in constipation assessment and management, or due to staffing availability, therefore, additional signposting may support other roles within the SPC setting to identify when their expertise is required across the assessment and management process.

Despite the clinical guideline's recommendation of the use of DRE, only $25 \%$ of patients received a DRE after three days without a bowel evacuation, however, clinical judgment is key to consider when interpreting this finding. Given the clinical pathology of many patients within SPC such as reduced mobility, reduced oral intake, and pharmacology, the cause of constipation can often be identified without an invasive procedure such as a DRE. In addition, almost half $(n=65 ; 43.3 \%)$ of the patients included in the chart review were admitted for end of life care. The guidelines state that when caring for a patient who is at the end of life, rectal intervention is rarely necessary [18], therefore, it was appropriate to see limited use of this intervention.

A palliative care approach calls for symptom management to be addressed as a multidimensional experience, considering the non-physical aspects of pain within assessment and management [34]. Pharmacological management was well developed and aligned to the guidelines, which state that the medication with lowest cost base should be used where there is no evidence to differentiate between medications in terms of efficacy, tolerability and side effect profile [18]. A Cochrane review of clinical trials highlighted no evidence to support the efficacy of one laxative over another [20], therefore, laxatives with a lower cost base should be selected. In the UK, Senna, lactulose, and docusate are the three oral laxatives with the lowest cost base $(£ 0.80, £ 1.30$, and $£ 1.95$ per 14 day treatment respectively [35]), and these options were used as primary laxatives for approximately half of patients (46.0\%), mirroring findings from previous hospicebased research in the UK and USA [10, 21]. However, findings highlighted that pharmacological strategies were more likely to be documented, resulting in a lack of evidence that 
non-pharmacological interventions were utilised and questioning the use of a holistic approach to care [36]. Best practice is based on a balance between strategies for prevention and self-care and prescribed oral and rectal laxative therapy [19], however, this is not reflected in the current study. Conversations around the prevention of constipation, which were a key element within the guidelines, were only recorded on $20 \%$ of patient charts. Whilst equal attention should be paid to optimised toileting, lifestyle modifications, and adjustment of activity levels [18] as well as pharmacological management, non-pharmacological interventions were only documented in $53 \%$ of case-notes, compared to 96\% documenting pharmacological intervention. These findings call for a greater awareness of the holistic approach necessary in the prevention and management of constipation in palliative care. Whilst patients may be implementing these independently of their hospice plan of care, preventative and non-pharmacological strategies are of equal relevance to pharmacological care and therefore should also be discussed by HCPs and recorded alongside pharmacological intervention.

Previous studies have shown that only a small proportion of the cost of managing constipation in a SPC inpatient unit was related to drug expenditure (13\%), compared to $85 \%$ of cost for staff time [37]. The cost to older adults can be seen in terms of the reported negative impact on physical, psychological, and social wellbeing in everyday life [38]. This cost to older adults was also found in a recent systematic review within SPC settings, therefore, it is essential that this symptom is well managed [8]. Good clinical record keeping is an integral component in good professional practice and the delivery of quality healthcare, and would enable enhanced communication within the MDT, reducing the staff time required to manage constipation [22, 23, 39]. Effective assessment and management of constipation through adherence to clinical guidelines along with good documentation of all aspects of assessment and management may assist in minimising the burden to both staff and patients.

Interpretation of the findings must be undertaken cautiously, due to the inability to differentiate between data that were not recorded, and clinical activities that were not undertaken. Non-recorded data limits the ability to provide a full picture of what happens in this setting regarding the assessment and management of constipation. However, this study is able to provide useful insights into data recording and some ways in which the problem of constipation is it being managed within this practice setting. Strengths of this research are also acknowledged. Through the use of Gilbert's [25] evaluative criteria, the methodological approach has been conducted in a rigorous manner, in particular the training and follow up verification with data abstractors after collecting five case- notes. This rigorous approach has increased the replicability of the study and reliability of the findings.

\section{Conclusions}

This study provides an insight into the recorded clinical practices of constipation assessment and management in inpatient SPC settings. Despite existing clinical guidelines, clinical records show great variability within and between sites. Whilst comprehensive, holistic assessments were evident for $73 \%$ of patients, a lack of standardised documentation or evidence of follow up may result in the identification, diagnosis, and subsequent treatment of constipation being missed for some patients within this setting. The nurse, supported by standardised documentation procedures, plays a key coordinating role in identifying and assessing constipation. Application of pharmacological interventions appeared to adhere to clinical guidelines, but prevention and non-pharmacological interventions requires further attention. Accurate documentation is essential for not only identifying areas of practice that require improvement, but areas of good practice. Further education is needed to equip HCPs with the knowledge and skills to perform not only a full assessment, but also to use appropriate non-pharmacological and preventative strategies. Owing to gaps in recording, it is vital that SPC settings consider ways to support the implementation of new documenting and recording strategies which are readily available to the MDT to enable transparency of care and maintain good clinical standards. Future research should consider identifying staff knowledge of constipation, and the use and effectiveness of non-pharmacological interventions across clinical settings for this group of patients.

\section{Endnotes}

${ }^{1}$ The ADAPTE process provides a systematic approach to adapting guidelines produced in one setting for use in a different cultural and organizational context. The adaptation consists of three main phases; set-up phase, adaptation phase, and finalization phase.

\section{Additional files}

Additional file 1: Management of Constipation in Adult Patients Receiving Palliative Care Guidelines Summary. (DOCX $326 \mathrm{~kb}$ )

Additional file 2: STROBE Statement-checklist of items that should be included in reports of observational studies. (DOCX $40 \mathrm{~kb}$ )

\section{Abbreviations}

BSC: Bristol Stool Chart; DRE: Digital rectal examination; HCPs: Healthcare Professionals; MDT: Multi-disciplinary team; OIC: Opioid induced constipation; ORECNI: Office for Research Ethics Committees Northern Ireland;

SPC: Specialist palliative care; UK: United Kingdom 


\section{Acknowledgements}

The authors would like to acknowledge members of the research steering group for their contribution to the design of the larger research project: Dr. John MacArtney, Professor Max Watson, and Mrs. Eileen Wright. We would also like to acknowledge Angela McAleer for clinical guidance, Rachel Perry for site coordination, and Mary Armstrong, Gail Watson, Rachel Grubb, Gemma Glover, Pippa Grundy and Robert Przekwas for undertaking the casenote reviews.

\section{Authors' contributions}

All authors made substantial contributions to the conception and design of the work. AF and LGW facilitated the acquisition of data, SM, DM, EB, PS, and FH led on interpreting and drafting the work, all authors revised it critically, and all authors read and approved the final version of the manuscript.

\section{Funding}

This work was supported by a research grant awarded to Professor Sonja Mcllfatrick by Marie Curie UK (REF MCCC-RP-16-A20993). The funding body had no role in the design of the study and collection, analysis, and interpretation of data and in writing the manuscript.

\section{Availability of data and materials}

The datasets used and/or analysed during the current study are available from the corresponding author on reasonable request.

\section{Ethics approval and consent to participate}

The study was approved by the Office for Research Ethics Committees Northern Ireland (ORECNI) (RECA Reference 16/WM/0352). Permission to access patient notes for the purpose of this study was obtained from each hospice. Approval was also obtained from the Hospice Research Governance Committees in each location. Data collection was conducted by hospice staff who routinely access patient notes, and all data was anonymised prior to sharing with the research team.

\section{Consent for publication}

Not applicable.

\section{Competing interests}

The authors declare that they have no competing interests.

\section{Author details}

IInstitute of Nursing and Health Research, Ulster University, Shore Road, Newtownabbey, Co Antrim BT37 OQB, UK. '² Marie Curie Hospice, Balornock Rd, Glasgow G21 3US, UK. ${ }^{3}$ Queen's University Belfast, University Rd, Belfast BT7 1NN, UK. " Marie Curie Hospice, Frogston Road West, Edinburgh EH10 7DR, UK. ${ }^{5}$ Université de Lausanne, Lausanne, Switzerland.

\section{Received: 18 April 2019 Accepted: 19 June 2019}

\section{Published online: 15 July 2019}

\section{References}

1. NICE. Constipation [Internet]. Clinical knowledge summaries. 2017 Jun [cited 2018 Dec 13]. Available from: https://cks.nice.org.uk/ constipation\#!topicsummary

2. Andrews A, Morgan G. Constipation management in palliative care: treatments and the potential of independent nurse prescribing. Int J Palliat Nurs. 2012;18(1):17-22 [cited 2016 Oct 7]. Available from: http://www. magonlinelibrary.com/doi/abs/10.12968/ijpn.2012.18.1.17.

3. Gallegos-Orozco JF, Foxx-Orenstein AE, Sterler SM, Stoa JM. Chronic constipation in the elderly. Am J Gastroenterol. 2012;107(1):18-25 [cited 2018 Dec 13]. Available from: http://www.ncbi.nlm.nih.gov/pubmed/21989145.

4. Rao SSC, Go JT. Update on the management of constipation in the elderly: new treatment options. Clin Interv Aging. 2010;5:163-71 [cited 2018 Dec 13]. Available from: http://www.ncbi.nlm.nih.gov/pubmed/20711435.

5. Fosnes GS, Lydersen S, Farup PG. Drugs and constipation in elderly in nursing homes: what is the relation? Gastroenterol Res Pract. 2012;2012: 290231 [cited 2018 Dec 13]. Available from: http://www.ncbi.nlm.nih.gov/ pubmed/22505881.

6. Mercadante S, Masedu F, Maltoni M, De Giovanni D, Montanari L, Pittureri $C$, et al. The prevalence of constipation at admission and after 1 week of palliative care: a multi-center study. Curr Med Res Opin.
2018;34(7):1187-92 [cited 2018 Aug 24]. Available from: http://www. ncbi.nlm.nih.gov/pubmed/28728515.

7. Clark K, Smith JM, Currow DC. The prevalence of bowel problems reported in a palliative care population. J Pain Symptom Manag. 2012;43(6):993-1000 [cited 2018 Jan 9]. Available from: http://www.ncbi.nlm.nih.gov/pubmed/22651945.

8. Muldrew DH, Hasson F, Carduff E, Clarke M, Coast J, Finucane A, et al. Assessment and management of constipation for patients receiving palliative care in specialist palliative care settings: a systematic review of the literature. Palliat Med 2018;026921631775251 [cited 2018 Feb 19]. Available from: http://www.ncbi.nlm.nih.gov/pubmed/29431016.

9. International Longevity Centre UK. The burden of constipation in our ageing population: working towards better solutions. Brussels; 2013.

10. Goodman M, Low J, Wilkinson S. Constipation management in palliative care: a survey of practices in the United Kingdom. J Pain Symptom Manag. 2005;29(3):238-44.

11. Tian H, Ding C, Gong J, Ge X, McFarland LV, Gu L, et al. An appraisal of clinical practice guidelines for constipation: a right attitude towards to guidelines. BMC Gastroenterol. 2016;16(1):52 [cited 2017 Aug 16]. Available from: http:// bmcgastroenterol.biomedcentral.com/articles/10.1186/s12876-016-0466-8.

12. The ADAPT Collection. The ADAPTE process: resource toolkit for guideline adaptation. Version 2.0 [internet]. 2009 [cited 2012 Jun 2]. Available from: https://www.g-i-n.net/document-store/working-groups-documents/ adaptation/adapte-resource-toolkit-guideline-adaptation-2-0.pdf.

13. Rome Foundation. Rome III diagnostic criteria [internet]. Rome III disorders criteria appendix. 2006. Available from: https://www.theromefoundation.org/ assets/pdf/19_Romelll_apA_885-898.pdf.

14. Bharucha AE, Dorn SD, Lembo A, Pressman A. American gastroenterological association medical position statement on constipation. Gastroenterology. 2013;144(1):211-7 [cited 2017 Aug 17]. Available from: http://www.ncbi.nlm. nih.gov/pubmed/23261064.

15. Larkin PJ, Sykes NP, Centeno C, Ellershaw JE, Elsner F, Eugene B, et al. The management of constipation in palliative care: clinical practice recommendations. Palliat Med. 2008;22(7):796-807.

16. Librach SL, Bouvette M, De Angelis C, Farley J, Oneschuk D, Pereira JL, et al. Consensus recommendations for the Management of Constipation in patients with advanced, progressive illness. J Pain Symptom Manag. 2010;40(5):761-73.

17. Lindberg G, Hamid SS, Malfertheiner P, Thomsen OO, Fernandez B, Garisch JJ, et al. World Gastroenterology Organisation global guideline: Constipation--a global perspective. J Clin Gastroenterol. 2011;45(6):483-7 [cited 2017 Aug 17]. Available from: https://umexpert.um.edu.my/file/ publication/00000557_79604.pdf.

18. National Clinical Effectiveness Committee. Management of Constipation in Adult Patients Receiving Palliative Care National Clinical Guideline No. 10 November 2015. 2015.

19. Larkin PJ, Cherny NI, La C, Guglielmo M, Ostgathe C, Scotte F, et al. Diagnosis, assessment and Management of Constipation in advanced Cancer: ESMO clinical practice guidelines. Ann Oncol. 2018;29(supplement 4):iv111-25 [cited 2019 Jan 30]. Available from: https://www.esmo.org/ Guidelines/Supportive-and-Palliative-Care/Diagnosis-Assessment-andManagement-of-Constipation-in-Advanced-Cancer.

20. Candy B, Jones L, Larkin PJ, Vickerstaff V, Tookman A, Stone P. Laxatives for the management of constipation in people receiving palliative care. Cochrane Database Syst Rev. 2015;(5) [cited 2016 Nov 4]. Available from: http://doi.wiley.com/10.1002/14651858.CD003448.pub4.

21. Sera L, McPherson ML, Holmes HM. Commonly prescribed medications in a population of hospice patients. Am J Hosp Palliat Med. 2014;31(2):126-31 [cited 2017 Aug 15]. Available from: http://www.ncbi.nlm.nih.gov/pubmed/ 23408370

22. General Medical Council. Code of Conduct [Internet]. 2015 [cited 2019 Apr 11]. Available from: https://www.gmc-uk.org/about/how-we-work/ governance/council/code-of-conduct

23. Nursing and Midwifery Council. The Code. Professional standards of practice for nurses, midwifes and nursing associates [internet]. Nursing and midwifery council. 2018 [cited 2019 Apr 11]. Available from: https://www. nmc.org.uk/globalassets/sitedocuments/nmc-publications/nmc-code.pdf

24. Peterson DE, Bensadoun RJ, Lalla R V., McGuire DB. Supportive care treatment guidelines: value, limitations, and opportunities. In: Seminars in oncology [internet]. 2011 [cited 2019 Jun 6]. p. 367-373. Available from: http://www.ncbi.nlm.nih.gov/pubmed/21600365.

25. Gilbert EH, Lowenstein SR, Koziol-McLain J, Barta DC, Steiner J. Chart reviews in emergency medicine research: where are the methods? Ann Emerg Med. 
1996;27(3):305-8 [cited 2018 May 17]. Available from: http://www.ncbi.nlm. nih.gov/pubmed/8599488.

26. Wickson-griffiths A, Kaasalainen S, Ploeg J, Mcainey C. Revisiting retrospective chart review: An evaluation of nursing home palliative and end-of-life care research. Palliat Med Care. 2014;1 (2):8 [cited 2017 Nov 23]. Available from: https://symbiosisonlinepublishing.com/palliative-medicinecare/palliative-medicine-care10.php.

27. von Elm E, Altman DG, Egger M, Pocock SJ, Gøtzsche PC, Vandenbroucke $J P$, et al. The strengthening the reporting of observational studies in epidemiology (STROBE) statement: guidelines for reporting observational studies. Ann Intern Med. 2007;147(8):573-7 [cited 2018 Nov 2]. Available from: http://www.ncbi.nlm.nih.gov/pubmed/17938396.

28. National Council for Palliative Care. National Survey of Patient Activity Data for Specialist Palliative Care Services [Internet]. London; 2016 [cited 2018 Feb 16]. Available from: http://www.endoflifecare-intelligence.org.uk/ resources/publications/mdsreport2014.

29. Fox-Wasylyshyn SM, El-Masri MM. Handling missing data in self-report measures [internet]. Vol. 28, research in nursing and health. Wiley-Blackwell; 2005 [cited 2018 Jun 29]. p. 488-495. Available from: http://doi.wiley.com/ 10.1002/nur.20100

30. Dong $Y$, Peng $C-Y$ J. Principled missing data methods for researchers. Springerplus. 2013;2(1):222 [cited 2018 Jun 29]. Available from: http://www. ncbi.nlm.nih.gov/pubmed/23853744.

31. National Institute for Clinical Excellence. Bristol Stool Chart. Guid Resour. 2013;

32. Mcllfatrick S, Hasson F. Evaluating an holistic assessment tool for palliative care practice. J Clin Nurs. 2014;23(7-8):1064-75 [cited 2017 Apr 11]. Available from: http://doi.wiley.com/10.1111/jocn.12320.

33. Sekse RJT, Hunskår I, Ellingsen S. The nurse's role in palliative care: a qualitative meta-synthesis. J Clin Nurs. 2018;27:e21-38 [cited 2019 Apr 17]. Available from: http://doi.wiley.com/10.1111/jocn.13912.

34. Wilkie DJ, Ezenwa MO. Pain and symptom management in palliative care and at end of life. Nurs Outlook. 2012;60(6):357-64 [cited 2018 Dec 17]. Available from: http://www.ncbi.nlm.nih.gov/pubmed/22985972.

35. Regional drugs and therapeutics Centre. Cost comparison charts [internet] 2018 [cited 2019 Apr 12]. Available from: http://gmmmg.nhs.uk/docs/cost comparison_charts.pdf.

36. Payne S, Seymour J, Ingleton C. Palliative care nursing : principles and evidence for practice [internet]. Open University Press; 2008 [cited 2018 Nov 2]. 717 p. Available from: https://catalogue.library.ulster.ac.uk/items/ 1217117? query=palliative+care+nursing\&resultsUri= items\%3Fquery\%3Dpalliative\%2Bcare\%2Bnursing\%26offset\%3D0.

37. Wee B, Adams A, Thompson K, Percival F, Burslem K, Jobanputra M. How much does it cost a specialist palliative care unit to manage constipation in patients receiving opioid therapy? J Pain Symptom Manag. 2010;39(4):64454 [cited 2017 Mar 23]. Available from: http://linkinghub.elsevier.com/ retrieve/pii/S0885392410000801.

38. Munch L, Tvistholm N, Trosborg I, Konradsen H. Living with constipation-older people's experiences and strategies with constipation before and during hospitalization. Int I Qual Stud Health Well-being. 2016; 11:30732 [cited 2019 Apr 12]. Available from: http://www.ncbi.nlm.nih.gov/ pubmed/27121271.

39. Mathioudakis A, Rousalova I, Gagnat AA, Saad N, Hardavella G. How to keep good clinical records. Breathe (Sheffield, England). 2016;12(4):369-73 [cited 2018 Dec 17]. Available from: http://www.ncbi.nlm.nih.gov/pubmed/28210323.

\section{Publisher's Note}

Springer Nature remains neutral with regard to jurisdictional claims in published maps and institutional affiliations.

Ready to submit your research? Choose BMC and benefit from:
- fast, convenient online submission
- thorough peer review by experienced researchers in your field
- rapid publication on acceptance
- support for research data, including large and complex data types
- gold Open Access which fosters wider collaboration and increased citations
- maximum visibility for your research: over 100M website views per year
At BMC, research is always in progress.
Learn more biomedcentral.com/submissions

